WEA 190050 Version 2.1. Accepted at Weather

18 October 2019

PREPRINT

\title{
An under-forecast snowstorm associated with a small but deep tropopause depression
}

\author{
David Smart ${ }^{1}$ and Keith Browning ${ }^{2}$
}

\section{Abstract}

Heavy snowfall across central-southern England on 1 February 2019 was associated with a quasi-stationary mesoscale depression of the tropopause which was evident in individual and combined water vapour (WV) and infra-red (IR) satellite imagery. Network radar imagery revealed the event as a slow moving area of precipitation beneath the tropopause depression, with embedded bands composed of heavier areas of precipitation. Precipitation amounts were under-forecast by the ECMWF (European Centre for Medium-range Weather Forecast) global model. The quality of the precipitation forecasts was better in those forecasts where the depth and columnar nature of the dynamical tropopause depression were well represented. A higher resolution mesoscale model hindcast has been used to reveal the presence of elevated convective precipitation generating cells associated with a layer of very weak CAPE above a frontal zone. The convection occurred directly beneath the tropopause depression which is thought to have played a role in generating it. The fact that the quality of the forecasts improved at very short lead times when the tropopause depression was represented better suggests that the scope for improvements in the model may depend on its capability to represent the small scale structure of the tropopause depression and its interaction with the underlying troposphere.

Keywords: snowfall; QPF; dynamical tropopause; convective destabilisation; forecast errors.

1 Research associate, UCL Hazard Centre, Dept of Earth Sciences, University College London, Gower St., London. WC16BE. Correspondence: d.smart@ucl.ac.uk Independent researcher, Bath, UK. 
36

37

\section{Introduction}

Despite advances in numerical weather prediction (NWP), accurate forecasting of localised heavy snowfall remains a challenge for operational meteorologists and the global and mesoscale models they employ. Frick and Wernli (2012) identified various issues with the forecasting of a high-impact snowfall event in north-west Germany, including model depiction of the critical moisture profile in the lower atmosphere and errors in the forecast snowfall amount and timing dependent on forecast lead time. Their analysis of European Centre for Medium-range Weather Forecasts (ECMWF) global model forecasts and a higher resolution mesoscale model 'hindcast' attributed reasons for the misforecasts to errors on various scales including the representation of an upperlevel trough as well as misplacement of a surface low-pressure system. More recently, Gascon et al (2015) reported on a disruptive and under-forecast snowfall event which occurred in central Spain. They suggested that a key role was played by a deeply penetrating tropopause fold, evident in satellite imagery as a dry intrusion (Browning, 1997).

In this article we examine another heavy snowfall event that was challenging to forecast. Snowfall amounts were greatly under-forecast and the location of the event was identified only in forecasts with lead times of 12 hours or less. The snowfall event occurred over central-southern England on 1 February 2019. On that day observers in Wiltshire, Hampshire, north-east Somerset and other parts of central-southern England awoke to steady snowfall which continued through the morning and into afternoon. Although the highest official total recorded was $19 \mathrm{~cm}$, there were widespread unofficial reports of at least $20 \mathrm{~cm}$, including photographic evidence of a level $\sim 27 \mathrm{~cm}$ at a location in Bath (Figure 1). Such amounts were sufficient to cause substantial disruption to travellers, transport infrastructure and public services, including power outages to thousands of homes.

This event was part of a series of incidents over a two-day period in southern England which included the stranding of motorists in south-west England due to heavy snowfall on the late afternoon of 31 January and again on the evening of 1 February in north Kent. The Met Office issued one severe weather warning for 31 January focused on SW England and at least four for central-southern England on 1 February- see NSWWS (2019). All these events appear to have been related to the passage of an upper-air disturbance, or disturbances, associated with a low-pressure system that moved southeastwards near to SW England. 
81

In the present article we focus on just the snowfall event in central-southern England during the morning of 1 February by describing the relationship between this major snowfall observed by radar and the upper-air structure as revealed by satellite imagery and two NWP models. We also examine the change in the quality of model predictions with decreasing forecast lead time and suggest possible reasons for shortcomings in model performance.

\section{Radar and satellite observations showing the association of the area of heavy snow with a mesoscale upper-level vortex and dry intrusion}

At 06 UTC on 1 February, a complex area of low pressure extended from Biscay to NW France with multiple surface and upper-level fronts over the Channel and southern England (Figure 2). Surface winds were generally light to moderate north-easterly over England. The Met Office network radar image valid at 12 UTC 1 February (Figure 3) shows a compact area of precipitation over central-southern England, most of which was falling as snow away from the coast. Embedded bands of enhanced snowfall can be seen. Animation of the imagery shows the area of heaviest snowfall to have been quasi-stationary during the morning of 1 February.

Figure 4 shows a 12-hour sequence of IR (infra-red) images from the MSG4 (Meteosat Second Generation) geostationary satellite leading up to the time of Figure 3. Figure 4(d) shows that the snow event occurred at the centre of a mesoscale cyclonic circulation. This circulation is revealed by the development of the curl of upper-level cloud seen in Figure 4(d). The mesoscale circulation, the centre of which is marked by a ' $X$ ' in the sequence of images, progressively distorted the original band of frontal cloud over the previous 12 hours, as seen in Figures 4(a-d), until the curl of high cloud almost enclosed the radar-detected area of snowfall. The area of snow at 12 UTC was not directly under the highest (brightest) cloud; rather the high cloud was circulating around it. This is best seen in Figures 4(c) and (d) where the snow is associated with the small area of less bright (lower) cloud beneath the 'X's.

Figure 5 is an enhanced MSG 'airmass' image for 1015 UTC on 1 February (for animated imagery see Eumetsat, 2019). An 'airmass' image is a blend of IR and WV (water vapour) images. The lighter shades in this kind of image represent clouds as seen in the IR and the red-tinted areas show drier upper-tropospheric air, seen as dark zones in grey-scale WV imagery (for an introduction to airmass imagery see Eumetrain, 2019). The blending of the RGB (Red-Green-Blue channels) images in Figure 5 reveals the curl of upper-level cloud as the brightest, almost white, area (labeled C). This area is 
113 seen to curl around the less bright area of lower cloud (labeled $X$ ) that was associated

114 with the snow over central-southern England; the snow cloud labelled $X$ is tinged with

$115 \mathrm{red} /$ orange due to the contribution from the $\mathrm{WV}$ channels because it was overlain by a

116 dry intrusion.

117

118

119

120

121

122

123

124

125

126

127

128

129

130

131

132

133

134

135

136

137

138

139

140

141

142

143

144

145

146

147

148

149

150

We show later (in the section presenting the NWP data) that the snowfall event occurred where this dry intrusion overran a low-level frontal zone over central-southern England. The origin of the dry intrusion is revealed in the sequence of single-channel (6.2 micron) WV images in Figure 6. These images have been colour enhanced so as to discriminate between moist, and/or cloudy air with low brightness temperature (yellow-green) and drier air in cloud-free regions of the mid-troposphere with high brightness temperature (dark blue). A number of dry intrusions (DIs) are evident and these are labelled ' 1 ', ' 2 ' and ' 3 '. They were associated with streams of dry air which moved eastwards in the synoptic scale flow. These streams were probably folded structures consisting partly of lower-stratospheric air intruding into the upper-mid troposphere.

The dry intrusion DI 2 was part of DI 1 which was left behind in a zone of stretching deformation as the rest of DI 1 advanced eastwards. DI 2 was still part of DI 1 at 2100/31 January (Figure 6(a)), but already at 2230 (Figure 6(b)) it can be seen becoming cut off. By the early hours of 1 February (Figure 6 (c and d)), DI 2 had been left behind near the south coast of England. Thereafter, for a time, DI 2 remained almost stationary over central-southern England (Figures 6 (e and f)), during which time its brightness temperature decreased (transition from dark blue to light blue) owing to the presence of the low/middle-level cloud that was producing the snow beneath the dry air of DI 2.

Dry intrusion DI 2 was seen to contain small 'hot spots' in brightness temperature in the WV imagery, corresponding to spots (small areas) where the dry air was penetrating slightly lower. These hot spots orbited within DI 2, at the centre of the area of cyclonic rotation that we inferred from IR imagery, and above the radar-detected area of snowfall. Figure 7 shows tracings between 06 and 14 UTC of two of these hot spots and it shows the pronounced rotation of the air at the top of the snow clouds. 
151 Global model results showing a small tropopause depression associated with the area of snow

153

We shall now examine results from the ECMWF global model validating at 12 UTC/1 February. First, in Figure 8, we look at results from the model run initialized at 12 UTC. Then, in Figure 9, we shall look at results from runs initialized at three earlier times.

Figure 8(a) depicts the model analysis of the height of the dynamical tropopause at 12 UTC. The dynamical tropopause is defined in terms of potential vorticity (PV) and is often used as a proxy for the actual tropopause. According to Kunz et al (2011), there is some variation in the value of $\mathrm{PV}$ that best defines the tropopause but we take 2PV units as a good indicator. Kunz et al suggest that this is generally an appropriate value for the Northern Hemisphere winter. Figure 8(a) shows a small but deep depression of the tropopause over central-southern England. It is co-located with the area where the satellite imagery revealed the stationary vortex/ rotating dry intrusion.

Figure 8(b) shows the forecast pattern of equivalent rainfall accumulation between 12 and 18 UTC, from which it is clear that the tropopause depression was associated with the major part of the heavy snowfall. This is consistent with there being a region of rising motion beneath a cyclonic upper-level PV anomaly, as described by Hoskins et al (1985). At first sight, this is encouraging evidence that the model was capable of resolving mesoscale processes leading to the snowfall event. However, although comparisons for spot locations are difficult, the global model appears to produce far less than the observed snow depth of $27 \mathrm{~cm}$ (roughly equivalent to $27 \mathrm{~mm}$ of rain) at Bath for example.

The results from three earlier runs of the ECMWF global model are presented in Figure 9. The left column depicts the height of the PV2 surface, valid at 12 UTC/1 Feb, initialised at lead times of (a) 36, (c) 24 and (e) 12 hours. The corresponding forecasts of accumulated precipitation at 18 UTC are depicted in the right column (b, $d$ and $f$ ). These forecasts appear to underestimate the maximum snow amount by at least 50\%; also, the degree of underestimation, and the positional error, increased with increasing lead time. Comparing the two columns, it is apparent that the errors in the position and intensity of the snowfall were associated with errors in the forecast position and depth of the mesoscale tropopause depression which also tended to increase with increasing lead time. Clearly, with the present generation of model, it is challenging to represent these rather small scale features except at very short lead times. 
188

189

190

191

192

193

194

195

196

197

198

199

200

201

202

203

204

205

206

207

208

209

210

211

212

213

214

215

216

217

218

219

220

221

222

223

224
A further complication is that, as shown later, there was a low-level baroclinic zone beneath the tropopause depression. It appears that the mesoscale upper-level cyclonic $\mathrm{PV}$ anomaly began to interact with this baroclinic zone to generate cyclonic PV at low levels (Hoskins et al, 1985). This probably accounts for the very low altitude of the PV2 surface (839hPa) as labeled in Figure 8(a).

\section{Mesoscale model results showing the convective nature of the area of snow}

The current version of the ECMWF global model has an equivalent grid spacing of around $9 \mathrm{~km}$ and 137 levels in the vertical. The horizontal grid spacing is such that it is not able to represent adequately the fine-scale structure of the area of snow. Therefore we have used a version of the Weather Research and Forecasting (WRF) model, nested down to a grid spacing of $3 \mathrm{~km}$ and incorporating a full and sophisticated set of parametrisations of moist processes. Owing to limitations in the availability of operational ECMWF data for this case, the simulations were initialised with forecasts from the National Centers for Environmental Prediction (NCEP) Global Forecast System (GFS).

Figure 10 shows plan views of the reflectivity field at (a) $700 \mathrm{hPa}$ and (b) $950 \mathrm{hPa}$, respectively derived from the model cloud microphysics scheme. The area of snow in Figure 10 (b) corresponds quite well with the observed area in Figure 3, although it extends farther towards the north-east. Some tendency for the heavier snow to be in bands orientated south-west to north-east is evident in both cases. There is also some smaller scale cellularity, especially at higher levels (Figure 10(a)). The bands are most evident at the upper level where one of them is highlighted by the dashed line $A A^{\prime}$ ' in Figure 10(a). The same line, $A A^{\prime}$, is reproduced again in Figure 10(b) but here the precipitation band is displaced from it owing to the sloping nature of the streams of falling precipitation.

Two cross-sections are shown in Figures 11(a) and (b). One of them (AA') is parallel to the snow bands and the other (BB') is orthogonal to them. Within the overall area of precipitation, both of these sections show two major streams of precipitation descending from near the 700-hPa level (3 km), as highlighted schematically by the dashed lines. The slope of these streams of precipitation is due to the precipitation particles generated aloft descending through layers in which the wind velocity differs from that at the level of initial generation. The wind shear responsible for this was occurring across the baroclinic (frontal) zone associated with the layer of closely spaced isopleths of potential temperature (thin contours). The precipitation was descending along 3-D 
trajectories and did not remain within either of these two cross sections. To a first approximation, one can visualize the heaviest precipitation being generated aloft as the yellow reflectivity in Figure 11(a) and then descending to lower levels as the yellow areas of reflectivity in Figure 11(b).

Banding of precipitation patterns is often attributed to the presence of conditional symmetric instability (CSI). Diagnosis of CSI is not straightforward (Schultz and Schumacher, 1999) and it requires the detection of the negative moist, saturated form of potential vorticity, MPV*, whilst excluding the presence of conditional instability. When conditional instability exists, potential energy can be converted into kinetic energy by upright convection rather than by means of the slantwise convection that characterises CSI. Weakly negative MPV* was found to be present in this case, mainly in a shallow layer close to the 700-hPa level (not shown). However, it coexisted with a layer of very weak convective instability (CAPE>0), outlined in Figures 11( $a$ and b) by the bold black contours $^{34}$. Thus our expectation of a role for CSI cannot be supported. Instead, a key factor influencing the fine-scale structure of the precipitation was the presence of shallow convective cells at the top of the precipitation. These would have been manifested in the pattern of precipitation by so-called generating cells (eg. Wexler and Atlas, 1959), corresponding to the upright portions at the top of the precipitation streamers highlighted by the dashed axes in Figure 11. Actual precipitation generating cells are likely to have had small horizontal dimensions of order $1 \mathrm{~km}$ and to have occurred in clusters. The model will have resolved the clusters rather than the individual cells.

A clear depiction of the clusters of precipitation generating cells and streamers is provided by the three-dimensional view of the model-derived pattern of reflectivity in Figure 12. This shows that the region of reflectivity in excess of $23 \mathrm{dBZ}$ was composed of a collection of upright generating cell clusters, each feeding a sloping streamer of precipitation. Most of the precipitation growth took place aloft, in the region of the generating cells. The growth of precipitation aloft is consistent with the colour shading in Figure 12 which shows that the strongest upward air motion (red $=30 \mathrm{~cm} / \mathrm{s}$ ) was within these generating cells. The temperature within the generating cells was between $-14 \mathrm{C}$ and $-7 \mathrm{C}$ which would have favoured precipitation growth by the Bergeron-

256 Findeisen process. from that grid point. It is defined as the accumulated buoyant energy from the Level of Free Convection (LFC) to the equilibrium level.

$7 \quad 4 \quad$ The CAPE seen at much lower levels in Figure 11 appears not to have been realized. 
257

258

259

260

261

262

263

264

265

266

267

268

269

270

271

272

273

274

275

276

277

278

279

280

281

282

283

284

285

286

287

288

289

290

291

292

293

294

295

\section{Conclusions}

We have shown that the heavy, disruptive snowfall that occurred in the UK across Wiltshire, Hampshire and NE Somerset on the morning of 1 February 2019 was associated with a mesoscale depression in the level of the tropopause which occurred above a low-level frontal zone. An upper-air disturbance that moved eastwards along the Channel coast evolved in-situ over central-southern England, eventually forming a quasi-stationary, almost symmetric mesoscale vortex at the lowered tropopause. The development of the tropopause depression was clearly revealed by infra-red and water vapour satellite imagery showing the formation of the accompanying dry intrusion and cyclonic circulation. The tropopause depression was associated with the pivoting of slow-moving bands composed of areas of heavy snowfall, seen most clearly in radar imagery.

An analysis of a mesoscale model hindcast of the event showed that much of the precipitation growth occurred within shallow convective generating cells at heights between about 2.5 and $3 \mathrm{~km}$. These fed sloping streamers of precipitation where the precipitation descended through the wind shear associated with the underlying frontal zone. The convection was associated with a shallow layer of CAPE above the frontal zone. The fact that the CAPE was very weak, in fact only marginally above zero, is consistent with an equilibrium being maintained between a dynamical mechanism creating the instability and its rapid release by the ongoing convection. According to Griffiths et al (2000), the upper-level potential vorticity anomaly associated with the tropopause depression could have provided the dynamical mechanism that was causing the convective destabilisation.

Performance of the operational ECMWF and GFS global models at predicting this event was rather poor at lead times exceeding 12 hours. The quality of the precipitation forecasts was better in those forecasts where the depth and columnar nature of the small tropopause depression were well represented. Future models will probably need to be able to represent such small dynamical features better if they are to generate realistic precipitation forecasts in these situations.

\section{Acknowledgements}

We are grateful to Prof David Schultz (University of Manchester) for discussion of the event and helpful comments on an earlier draft of this article. We thank two anonymous reviewers, one of whom provided particularly insightful remarks which were 
296 incorporated into the final manuscript. Radar data were provided by the British

297 Atmospheric Data Centre (BADC) and satellite imagery data by EUMETSAT. Figure 12 298 was prepared using the Unidata IDV (Integrated Data Viewer) and the RIP4 analysis 299 package (NCAR/ Mark Stoelinga).

300

301

302

\section{References}

303

304 Browning, K. A. 1997: The dry intrusion perspective of extra-tropical cyclone development, Meteorol.

305 Appl., 4, 317-324.

306 DWS, 2019: Met Office Daily Weather Summary February 2019, available at

307 https://digital.nmla.metoffice.gov.uk/collection_86058de1-8d55-4bc5-8305-5698d0bd7e13/;

308 accessed 26 March 2019).

309 Eumetsat, 2019:

310 https://www.eumetsat.int/website/home/Images/ImageLibrary/DAT_4256040.html_; accessed 26

311 March 2019).

312 Eumetrain, 2019: http://www.eumetrain.org/rgb_quick_guides/quick_guides/AirmassRGB.pdf;

313 accessed 22 July 2019).

314 Frick, C. and H. Wernli, 2012. A Case Study of High-Impact Wet Snowfall in Northwest Germany (25-27

315 November 2005): Observations, Dynamics, and Forecast Performance. Wea. Forecasting, 27, 1217-1234.

316 Gascón, E., Sánchez J.L, Charalambous, D., Fernández-González, S., López, L., García-Ortega, E.,

317 Merino, A., 2015: Numerical diagnosis of a heavy snowfall event in the center of the lberian Peninsula.

318 Atmospheric Research, 153, 250-263. doi: 10.1016/j.atmosres.2014.08.001.

319 Griffiths, M., Thorpe, A. J. and Browning, K. A., 2000: Convective destabilization by a tropopause fold

320 diagnosed using potential-vorticity inversion. Q.J.R. Meteorol. Soc., 126: 125-144.

321 doi: $10.1002 /$ aj.49712656207

322 Hoskins, B. J., McIntyre, M. E. and Robertson, A. W., 1985: On the use and significance of isentropic

323 potential vorticity maps. Q.J.R. Meteorol. Soc., 111: 877-946. doi: $\underline{10.1002 / q i .49711147002}$

324 Kunz, A., Konopka, P., Müller, R., and Pan, L. L., 2011. Dynamical tropopause based on isentropic

325 potential vorticity gradients, J. Geophys. Res., 116, D01110, doi:10.1029/2010JD014343.

326 NSWWS, 2019: https://digital.nmla.metoffice.gov.uk/SO d21ceb1e-6227-4f96-8248-

327 10f2e0ffbf98/; accessed 10 October 2019.

328 
329

330

Schultz, D.M. and P.N. Schumacher, 1999: The Use and Misuse of Conditional Symmetric Instability. Mon. Wea. Rev., 127, 2709-2732.

Wexler, R. and D. Atlas, 1959: Precipitation generating cells, J. Meteorol., 16, 327-332.

\section{Figure Captions}

Figure 1: Snowfall in Bath on 1 February 2019. A level depth of $27 \mathrm{~cm}$ was reported by the photographer. (Source: Roger Stone/Twitter)

Figure 2: Met Office analysis (ASXX) valid 06 UTC 1 February 2019. (Crown copyright)

Figure 3: Network radar image for 12 UTC 1 February 2019 showing the area of snowfall over centralsouthern England. The location of Bath is indicated by the white + . The colour scale indicates the equivalent rainfall rate in $\mathrm{mm} / \mathrm{hr}$ derived from the radar reflectivity. (Original data from Met Office/ BADC)

Figure 4: Enhanced infrared MSG imagery for (a) 00, (b) 04, (c) 08, (d) 12 UTC 1 February 2019. The red ' $X$ ' in each frame denotes the centre of the mesoscale cyclonic circulation that was distorting the pattern of upper-level cloud. The red box in (d) indicates the location of Figure 3. (Original data from EUMETSAT)

Figure 5: Enhanced MSG 'airmass' image for 1015 UTC 1 February 2019. Clouds are shaded white whilst dry air in the upper-mid troposphere is shaded red-orange. See text for annotations. (Original image from EUMETSAT)

Figure 6: Enhanced 6.2 micron water vapour (WV) imagery for a) 2100, (b) 2230 UTC 31 January, (c) 0100, (d) 0230, (e) 0500 and (f) 1130 UTC 1 February 2019. Clouds are shaded yellow-green whilst dry air in the upper-mid troposphere is shaded blue, the driest and/or lowest-penetrating dry air being dark blue. The numbers plotted in these images relate to dry intrusions referred to in the text. (Original data EUMETSAT)

Figure 7: Tracings of two sub-areas of relatively warm pixels in the 6.2 micron WV imagery between 0600 and 14001 February 2019. The approximate area of heavy snowfall is shaded light blue.

Figure 8: Output from the ECMWF global model initialized at 12 UTC on 1 February. (a) Model analysis of the pressure of the PV2 surface at 12 UTC 1 February 2019, shaded 240-400 hPa / dark green - light green, $400-660 \mathrm{hPa}$ / light orange- dark red, $660-680 \mathrm{hPa} /$ magenta, $>680 \mathrm{hPa} /$ white. The label ' 839 ' is explained in the text. (b) $6 \mathrm{~h}$ forecast of equivalent rainfall accumulation for the period 12 to 18 UTC, shaded from 1-3 mm light green, 3-5 mm green, 5-10 mm dark green. Solid contours representing MSLP and 10-m wind barbs are also shown. The approximate area of the part of the mesoscale model domain shown in subsequent figures is indicated by the red box. (Original plots courtesy Icelandic Met Office/ ECMWF) 
371

372

373

374

375

376

377

378

379

380

381

382

383

384

385

386

387

388

389

390

391

392

393

394

395

396

397

398

399

400

401

402

403

404

405

406

407

408

409

410

411

412

413
Figure 9: Three ECMWF global model forecasts, all valid at 12 UTC 1 February 2019. The left column shows the pressure of the PV2 surface from forecasts initialised at lead times of (a) 36, (c) 24 and (e) 12 hours. The annotated numbers indicate the pressure of the lowest level reached by the PV2 surface diagnosed in the model. The right column shows equivalent rainfall accumulation for the period 12 to 18 UTC forecast at similar lead times ( $b, d$ and $f$ ). Solid contours representing MSLP and 10-m wind barbs are also shown. The colour scales are as in Figure 8, plus light blue for totals of 10 to $15 \mathrm{~mm}$. (Original plots courtesy Icelandic Met Office/ ECMWF)

Figure 10: Plan views of the area of snow obtained from the $T+6 h$ forecast from the mesoscale model valid at 12 UTC 1 February 2019, showing model reflectivity (dBZ, shaded according to the colour scale). Plan views are shown in (a) for $700 \mathrm{hPa}$ and (b) for $950 \mathrm{hPa}$ on an approximately $240 \times 240 \mathrm{~km}$ subsection of the mesoscale computational domain. The locations of the cross-sections in Figure $11(a, b)$ are indicated.

Figure 11: Cross-sections through the shallow area of snow along AA' and BB' in Figure 10(a,b). Modelderived reflectivity is shaded in colour as in Figure 10(a,b). Relative humidity is shaded in grey scale, with white indicating moist air and grey dry air. The thin black contours show potential temperature $(K)$. The region centred near $800 \mathrm{hPa}$ where these are closely packed corresponds to the low-level frontal zone. Two major precipitation streamers in each section, evident as maxima in the model reflectivity field, are indicated by the dashed lines. The thick solid contours enclose regions of weakly positive CAPE (just marginally $>0$ ).

Figure 12: Three-dimensional view of the snow streamers obtained from the $T+6 \mathrm{~h}$ forecast from the mesoscale model valid at 12 UTC 1 February 2019, showing a sub-set of the computational domain $4 \mathrm{~km}$ high and approximately $240 \times 240 \mathrm{~km}$ across as viewed from the west. The 3D isosurface depicts a model reflectivity of $23 \mathrm{dBZ}$, corresponding to a moderate snowfall intensity and has been shaded according to vertical air velocity (see colour scale). Note the cellular and sloping nature of the streamers and the strong upward vertical velocities at their top between about 2.5 and $3 \mathrm{~km}$ consistent with the presence of shallow cells of upright convection at that level. The model reflectivity field at $100 \mathrm{~m}$ above the surface is shaded in grey, showing the full extent of light surface precipitation. The coastlines of southern England and the Bristol Channel are indicated in green.

.

(1)

(0)

(1)

1




\section{Figures and captions}

415

416

417

418

419

420

421

422

423

424

425

426

427

428

429

430

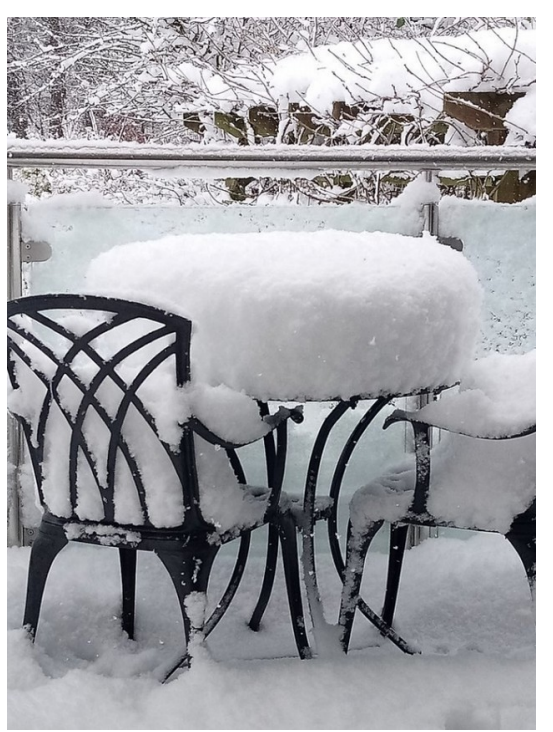

431

432

433

434

435

436

437

438

439

440

441

442

443

444

445

446

447

Figure 1: Snowfall in Bath on 1 February 2019. A level depth of $27 \mathrm{~cm}$ was reported by the photographer. (Source: Roger Stone/Twitter)

448

449

450

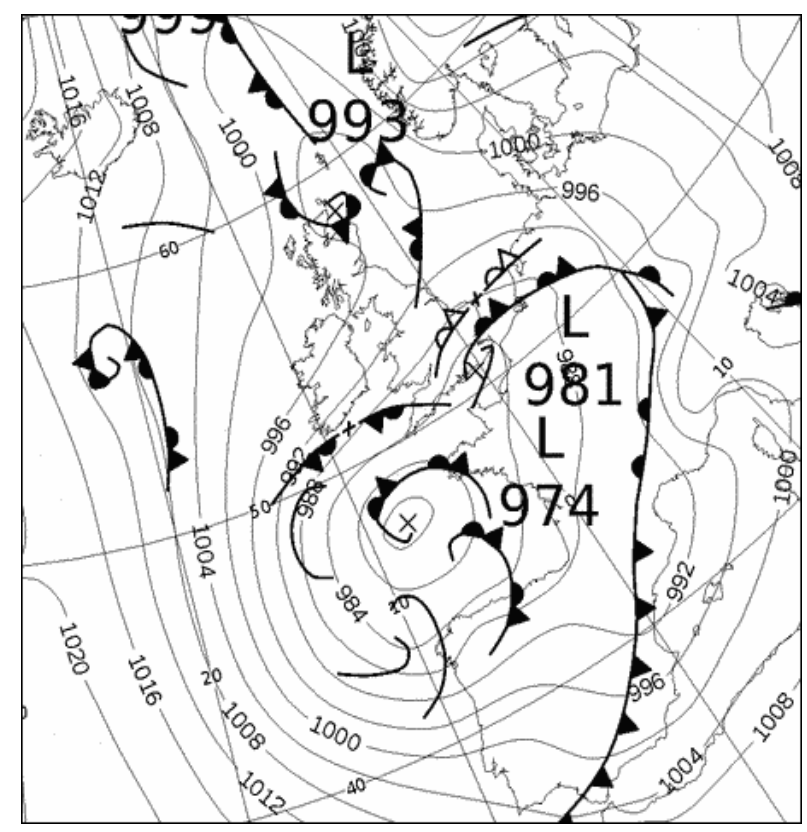

Figure 2: Met Office analysis (ASXX) valid 06 UTC 1 February 2019. (Crown copyright)

451

452 
453

454

455

456

457

458

459

460

461

462

463

464

465

466

467

468

469

470

471

472

473

474

475

476

477

478

479

480

481

482

483

484

485

486

487

488

489

490

491

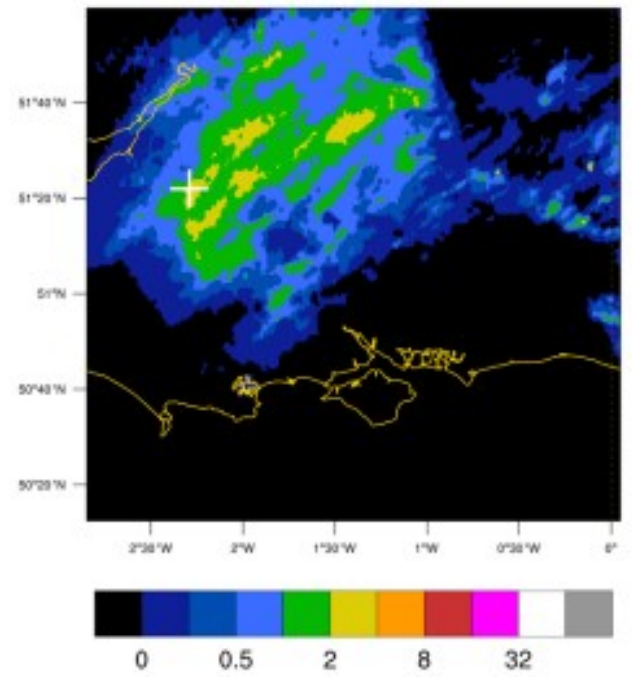

Figure 3: Network radar image for 12 UTC 1 February 2019 showing the area of snowfall over central-southern England. The location of Bath is indicated by the white + . The colour scale indicates the equivalent rainfall rate in $\mathrm{mm} / \mathrm{hr}$ derived from the radar reflectivity. (Original data from Met Office/ BADC)
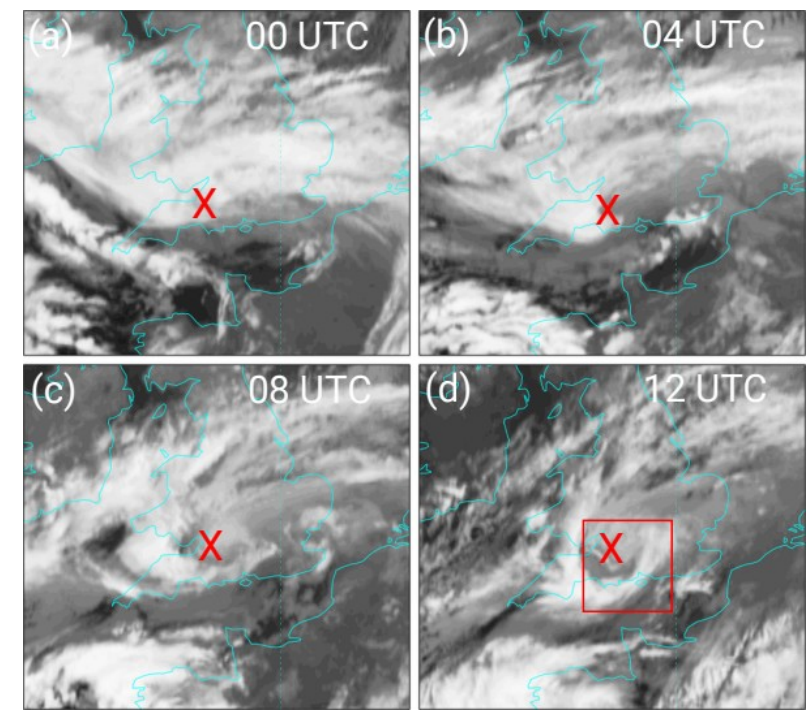

Figure 4: Enhanced infrared MSG imagery for (a) 00, (b) 04, (c) 08, (d) 12 UTC 1 February 2019. The red ' $X$ ' in each frame denotes the centre of the mesoscale cyclonic circulation that was distorting the pattern of upper-level cloud. The red box in (d) indicates the location of Figure 3 . (Original data from EUMETSAT) 
492

493

494

495

496

497

498

499

500

501

502

503

504

505

506

507

508

509

510

511

512

513

514

515

516

517

518

519

520

521

522

523

524

525

526

527

528

529

530

531

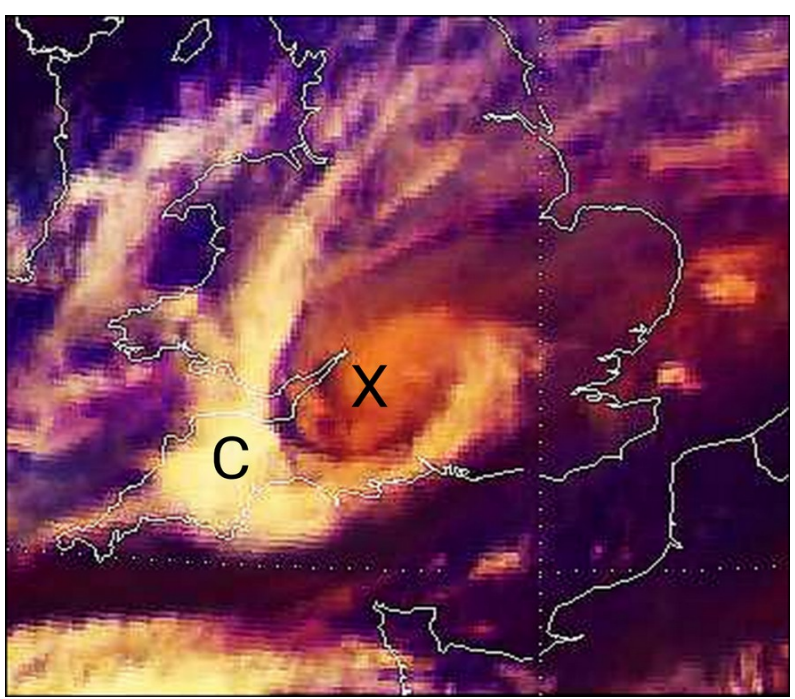

Figure 5: Enhanced MSG 'airmass' image for 1015 UTC 1 February 2019. Clouds are shaded white whilst dry air in the upper-mid troposphere is shaded red-orange. See text for annotations. (Original image from EUMETSAT) 
532

533

534

(a)

201901312100

535

536

537

538

539

540

541

542

543

544

545

546

547

548

549

550

551

552

553

554

555

556

557

558

559

560

561

562

563

564

565

566

567

568

569

570

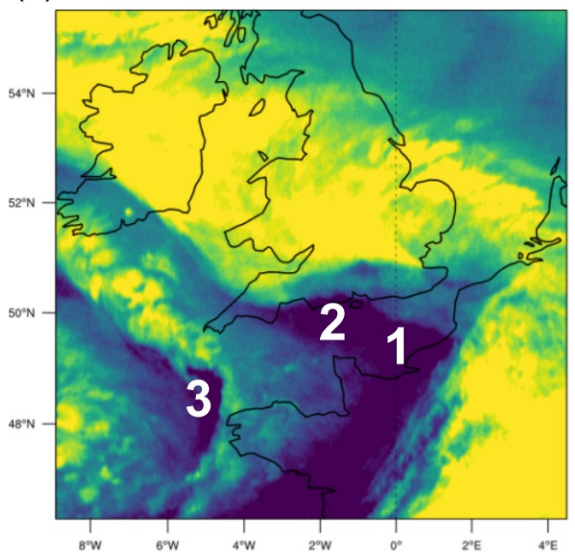

(b)

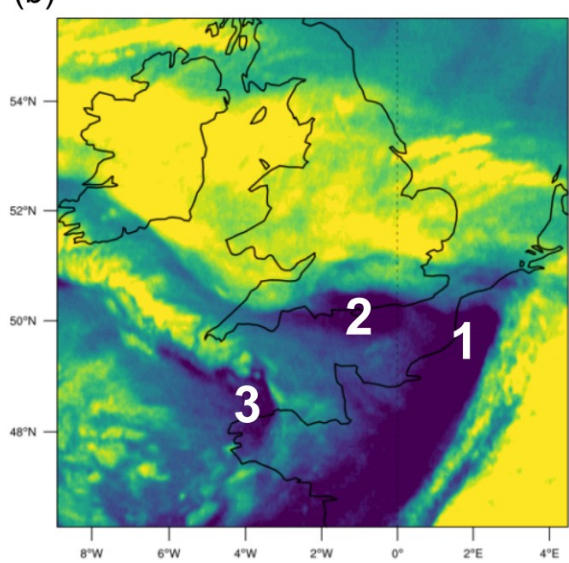

(c)

201902010100

(d)
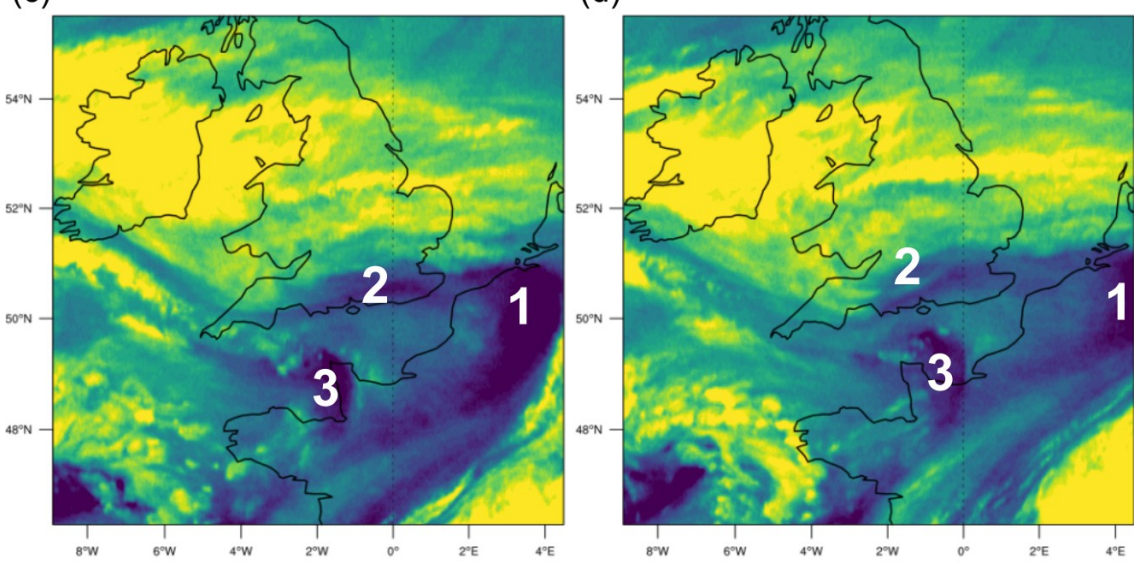

(e)

201902010500

(f)

201902011130
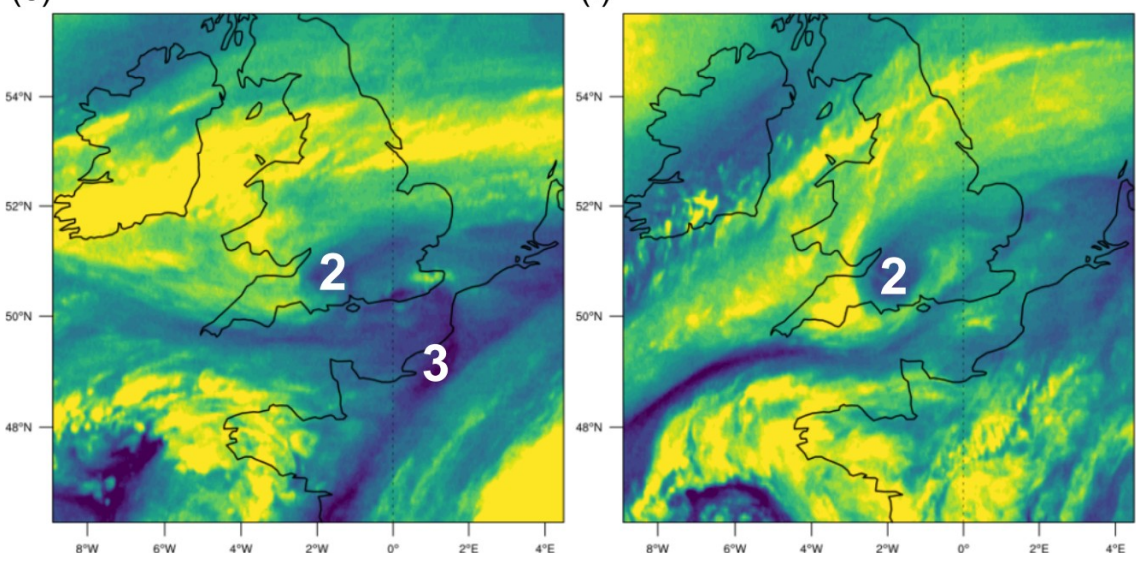

Figure 6: Enhanced 6.2 micron water vapour (WV) imagery for a) 2100, (b) 2230 UTC 31 January, (c) 0100, (d) 0230, (e) 0500 and (f) 1130 UTC 1 February 2019. Clouds are shaded yellow-green whilst dry air in the upper-mid troposphere is shaded blue, the driest and/or lowest-penetrating dry air being dark blue. The numbers plotted in these images relate to dry intrusions referred to in the text. (Original data EUMETSAT) 
572

573

574

575

576

577

578

579

580

581

582

583

584

585

586

587

588

589

590

591

592

593

594

595

596

597

598

599

600

601

602

603

604

605

606

607

608

609

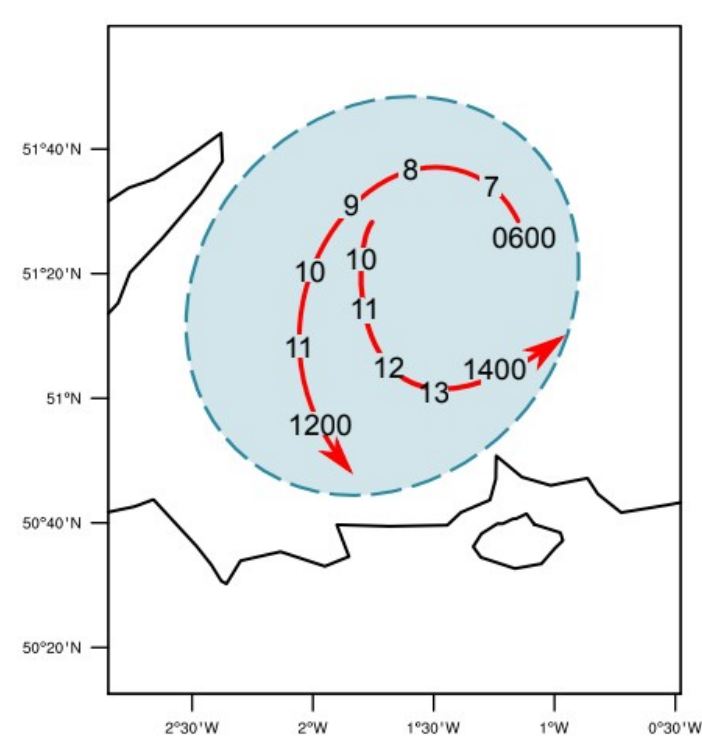

Figure 7: Tracings of two sub-areas of relatively warm pixels in the 6.2 micron WV imagery between 0600 and 14001 February 2019. The approximate area of heavy snowfall is shaded light blue.
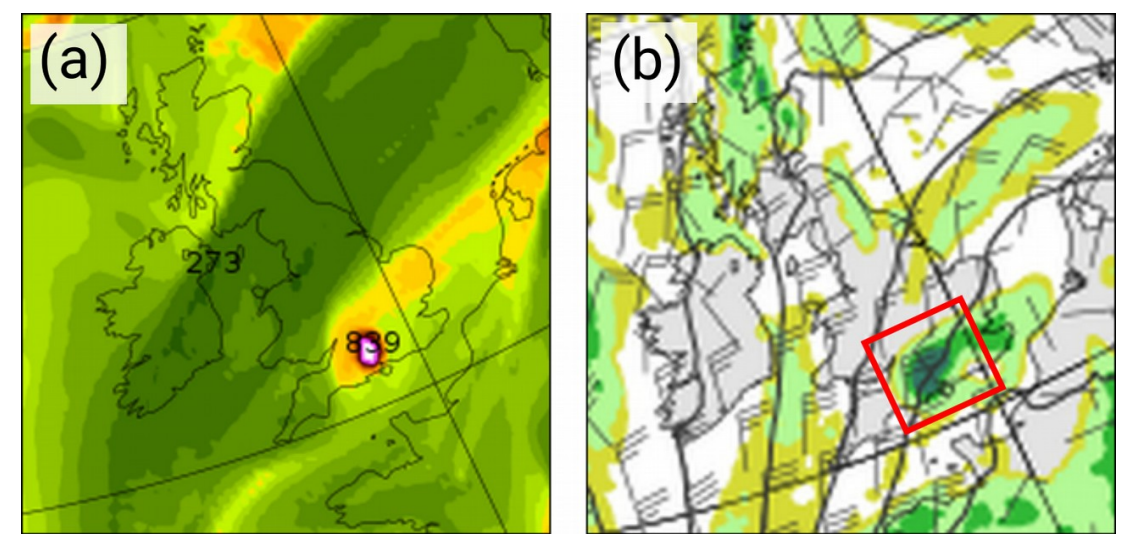

Figure 8: Output from the ECMWF global model initialized at 12 UTC on 1 February. (a) Model analysis of the pressure of the PV2 surface at 12 UTC 1 February 2019 , shaded $240-400 \mathrm{hPa}$ / dark green - light green, 400-660 hPa / light orange- dark red, 660-680 hPa / magenta, >680 hPa / white. The label ' 839 ' is explained in the text. (b) $6 \mathrm{~h}$ forecast of equivalent rainfall accumulation for the period 12 to 18 UTC, shaded from 1-3 mm light green, 3-5 $\mathrm{mm}$ green, 5-10 mm dark green. Solid contours representing MSLP and 10-m wind barbs are also shown. The approximate area of the part of the mesoscale model domain shown in subsequent figures is indicated by the red box. (Original plots courtesy Icelandic Met Office/ ECMWF) 
610

611

612

613

614

615

616

617

618

619

620

621

622

623

624

625

626

627

628

629

630

631

632

633

634

635

636

637

638

639

640

641

642

643

644

645

646

647

648

649

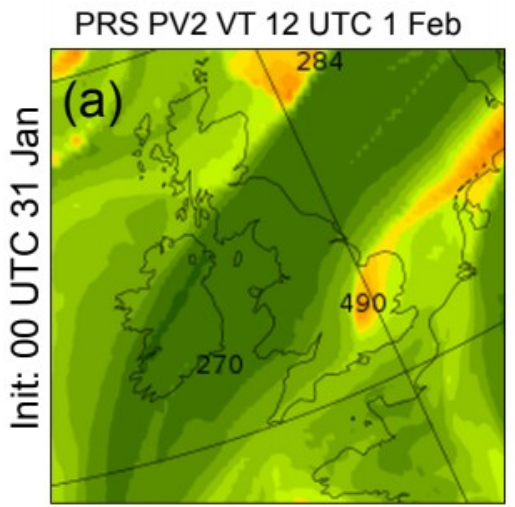

Acc. PPN VT 18 UTC 1 Feb
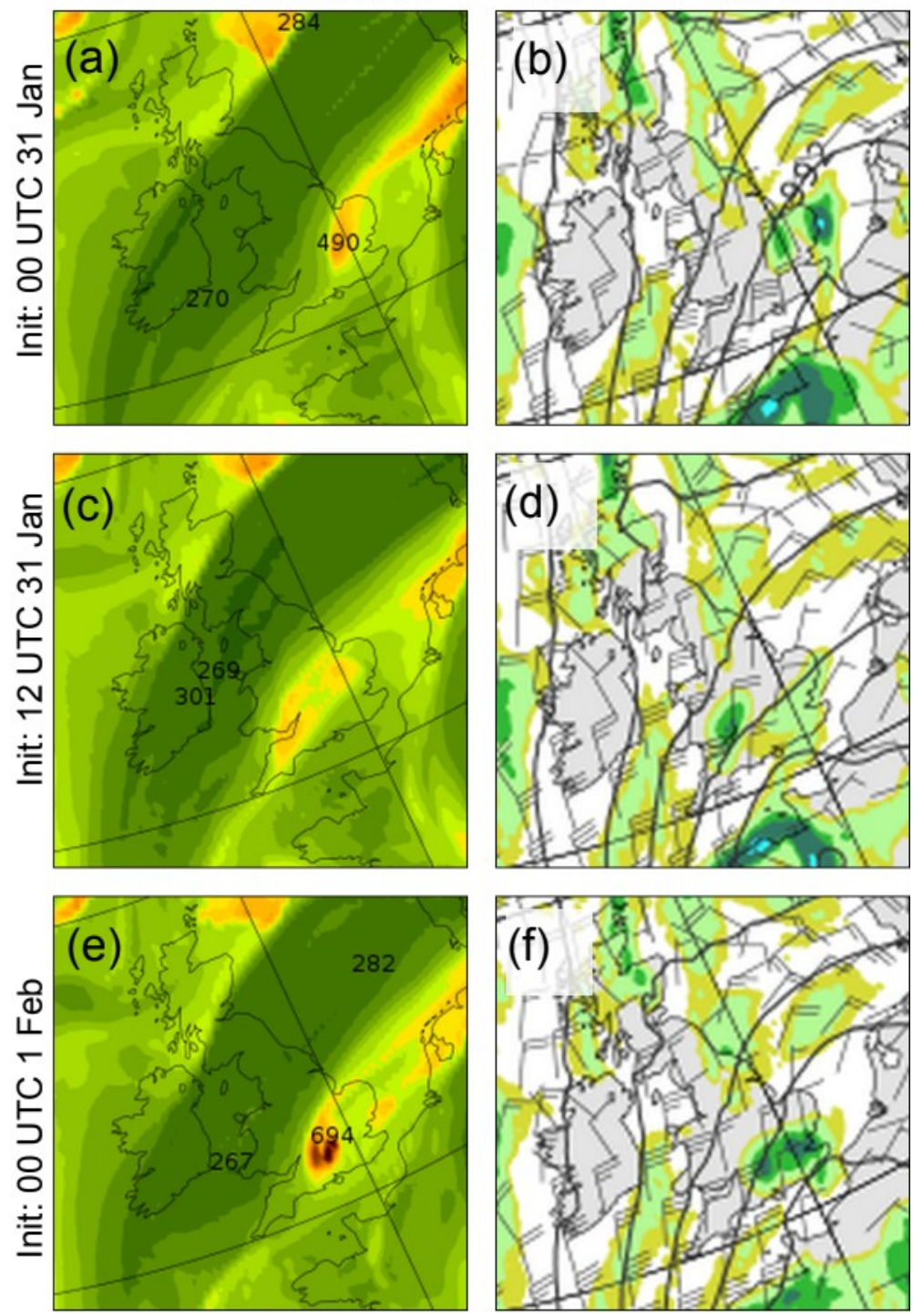

Figure 9: Three ECMWF global model forecasts, all valid at 12 UTC 1 February 2019. The left column shows the pressure of the PV2 surface from forecasts initialised at lead times of (a) 36, (c) 24 and (e) 12 hours. The annotated numbers indicate the pressure of the lowest level reached by the PV2 surface diagnosed in the model. The right column shows equivalent rainfall accumulation for the period 12 to 18 UTC forecast at similar lead times (b, $d$ and f). Solid contours representing MSLP and 10-m wind barbs are also shown. The colour scales are as in Figure 8 , plus light blue for totals of 10 to $15 \mathrm{~mm}$. (Original plots courtesy Icelandic Met Office/ ECMWF) 
650

651

652

653

654

655

656

657

658

659

660

661

662

663

664

665

666

667

668

669

670

671

672

673

674

675

676

677

678

679

680

681

682

683

684

685

686

687

688

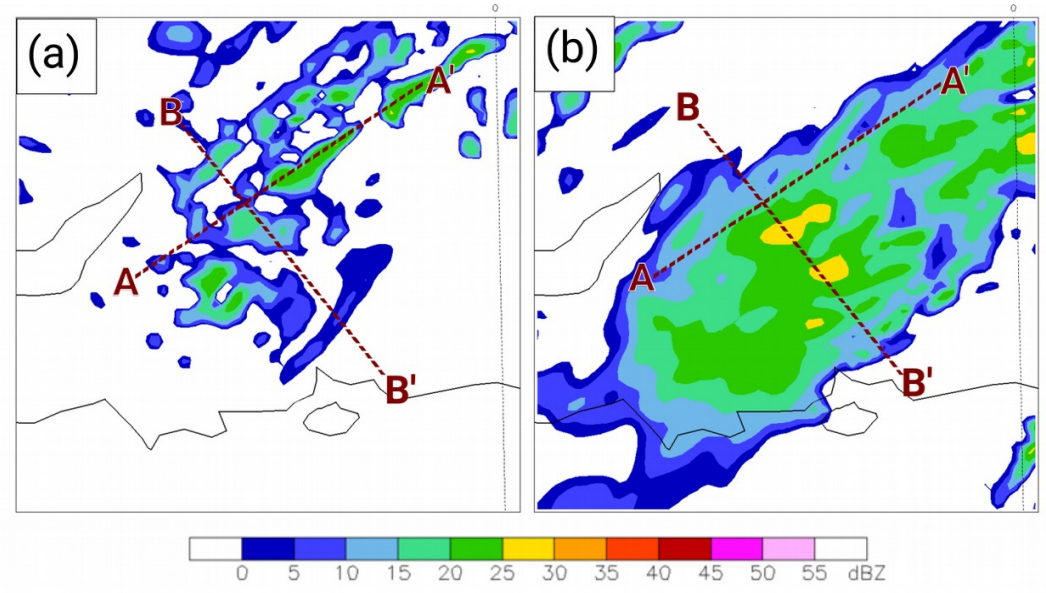

Figure 10: Plan views of the area of snow obtained from the T+6h forecast from the mesoscale model valid at 12 UTC 1 February 2019, showing model reflectivity (dBZ, shaded according to the colour scale). Plan views are shown in (a) for $700 \mathrm{hPa}$ and (b) for $950 \mathrm{hPa}$ on an approximately $240 \times 240 \mathrm{~km}$ sub-section of the mesoscale computational domain. The locations of the cross-sections in Figure 11(a,b) are indicated.
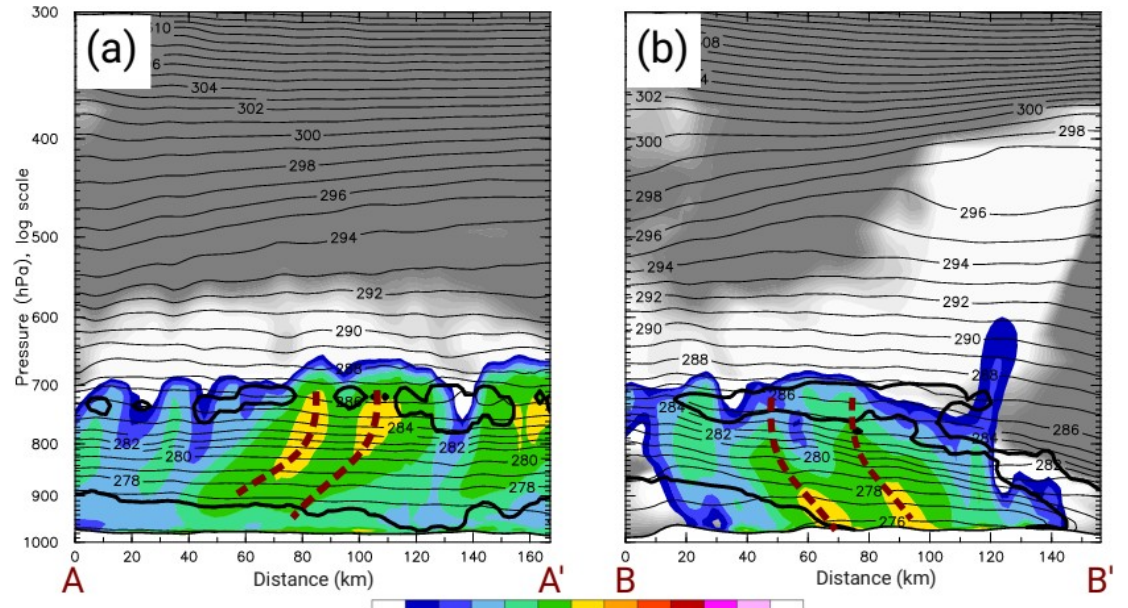

Figure 11: Cross-sections through the shallow area of snow along AA' and BB' in Figure 10(a,b). Model-derived reflectivity is shaded in colour as in Figure 10(a,b). Relative humidity is shaded in grey scale, with white indicating moist air and grey dry air. The thin black contours show potential temperature (K). The region centred near $800 \mathrm{hPa}$ where these are closely packed corresponds to the low-level frontal zone. Two major precipitation streamers in each section, evident as maxima in the model reflectivity field, are indicated by the dashed lines. The thick solid contours enclose regions of weakly positive CAPE (just marginally $>0$ ). 
689

690

691

692

693

694

695

696

697

698

699

700

701

702

703

704

705

706

707

708

709

710

711

712

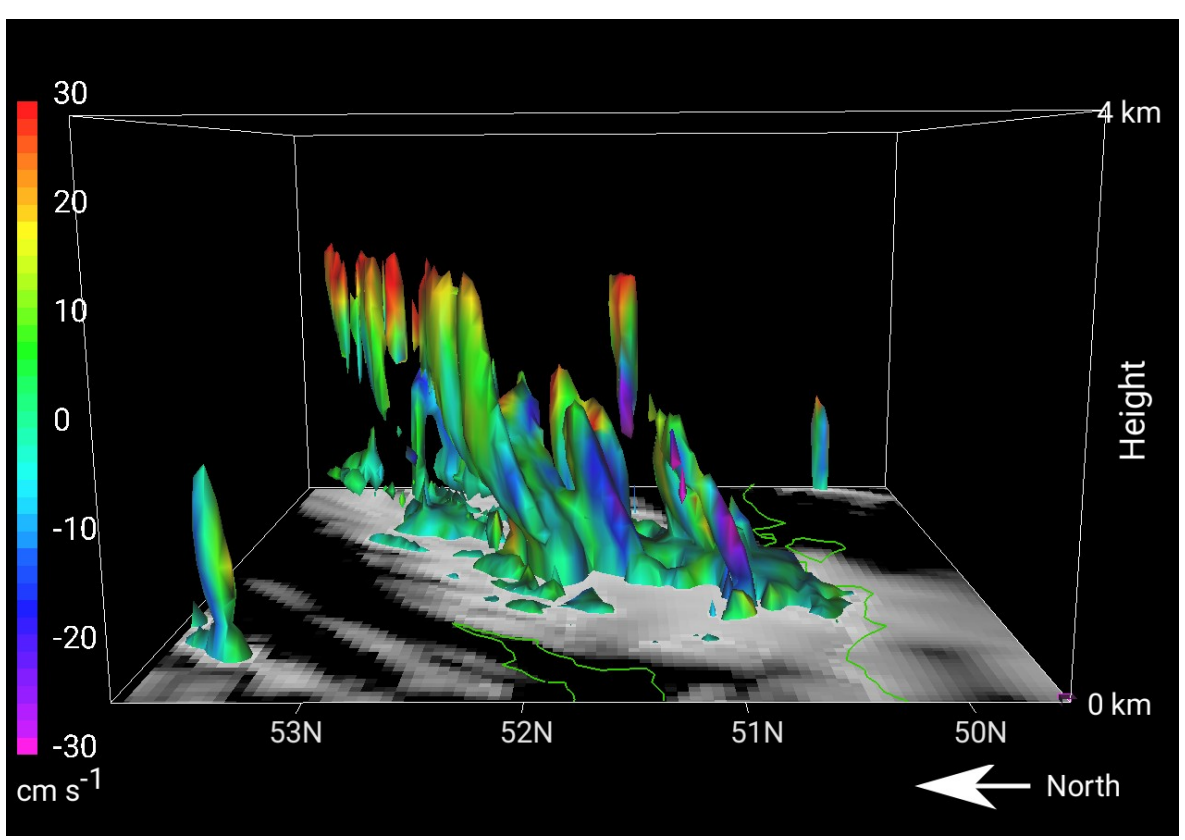

Figure 12: Three-dimensional view of the snow streamers obtained from the $T+6 \mathrm{~h}$ forecast from the mesoscale model valid at 12 UTC 1 February 2019, showing a sub-set of the computational domain $4 \mathrm{~km}$ high and approximately $240 \times 240 \mathrm{~km}$ across as viewed from the west. The 3D isosurface depicts a model reflectivity of $23 \mathrm{dBZ}$, corresponding to a moderate snowfall intensity and has been shaded according to vertical air velocity (see colour scale). Note the cellular and sloping nature of the streamers and the strong upward vertical velocities at their top between about 2.5 and $3 \mathrm{~km}$ consistent with the presence of shallow cells of upright convection at that level. The model reflectivity field at $100 \mathrm{~m}$ above the surface is shaded in grey, showing the full extent of light surface precipitation. The coastlines of southern England and the Bristol Channel are indicated in green. 